\title{
LA AUTONOMÍA COMO PROYECTO: PROCESOS DE REFLEXIÓN DELIBERADA EN EXPERIENCIAS DE AUTOGESTIÓN
}

\author{
Ana Inés Heras \\ heras@irice-conicet.gov.ar \\ David Burin, Teté Di Leo, Carlos Durañona, Mariano \\ Jaureguiberry, María Amalia Miano, Mariana Pacheco, \\ Mariela Rocco; con la colaboración de Jorgelina Flury, \\ María Lamacchia, Pablo Medrano \\ Instituto para la Inclusión Social y el Desarrollo Humano \\ IRICE-CONICET
}

\section{RESUMEN}

Presentamos un análisis sobre el trabajo de organizaciones colectivas orientadas por el concepto de democracia como régimen de sentido (Castoriadis 1997). Examinamos las reflexiones, los debates y los intercambios entre participantes de cinco proyectos autogestionados en la Argentina actual y la relación entre dichos procesos con un espacio que reúne a representantes de esos mismos colectivos, denominado Mesa Colectiva de Trabajo. Destacamos algunos conceptos de la obra de Castoriadis desde la cual examinamos nuestra práctica y, a la vez, al examinarla sostenemos la posibilidad de generar una conceptualización que se constituya en aporte a la institucionalización de la autogestión y a la autonomía como proyecto político. En particular, trabajamos con el concepto de reflexión deliberada y examinamos su efectiva posibilidad como práctica que otorgue espesor al proyecto de autonomía.

Palabras clave: autogestión, autonomía como proyecto, reflexión deliberada. 


\title{
AUTONOMY AS A PROJECT: DELIBERATE REFLECTION PROCESSES ON EXPERIENCES OF SELF-GOVERNMENT
}

\begin{abstract}
The authors present an analysis of the work conducted by collective organizations that are oriented by the concept of democracy understood as a meaningful regime (Castoriadis 1997). They examine the reflections, debates and exchanges between participants of five self-governed projects in contemporary Argentina and the relationship between these processes and a convergence of representatives of these collectives, called Mesa Colectiva de Trabajo (Collective Working Group). They highlight some of the concepts appearing in Castoriadis' work which they use to examine their own practice. At the same time, through this examination, they posit the possibility of generating a conceptualization that could become a contribution to the institutionalization of selfgovernment and autonomy as a political project. In particular, they work with the notion of deliberate reflection and examine its effectiveness as a practice that grants greater depth to autonomy as a project.
\end{abstract}

Key words: self-government, autonomy as a project, deliberate reflection. 


\section{MAPA DE RUTA}

Este escrito está organizado en cinco secciones. En la primera exponemos las cuestiones que nos impulsan a pensar juntos tomando en cuenta algunos conceptos centrales de la autonomía como proyecto. En la segunda comentamos los métodos que nos propusimos para pensar de modo colectivo sobre lo que exponemos aquí y los interrogantes que guiarán nuestra exposición. En la tercera trabajamos sobre el análisis de registros sobre la labor autogestionada de algunos colectivos específicos. La cuarta sección busca establecer puentes entre pensamientos y materialidades, tomando un ángulo de interpretación de aspectos que nos interesa destacar como aportes a la autogestión y la autonomía como proyecto. Por último, la quinta sección deja reflejadas nuestras conclusiones preliminares y abre interrogantes nuevos. El tema ${ }^{1}$ que va recorriendo todas las secciones es el de la reflexión deliberada. En tanto el tema se ha construido a varias voces, ya que somos once autores y colaboradores, las tonalidades vocales de quienes participamos en la generación de este artículo se han ido alternando o sumando para producir conjuntamente secciones enteras de nuestro trabajo. Por eso la textura varía y el lector se encontrará con estilos diferentes que pretenden reflejar nuestra alteridad colectiva.

\section{PREOCUPACIONES CENTRALES QUE DAN SENTIDO A NUESTRO TRABAJO}

En Argentina existe una larga tradición de grupos que se autoconvocan para producir acción en campos variados: político, social, laboral, cultural, artístico. Si bien estos grupos pueden tener un eje central (por ejemplo, laboral, cultural, o social) también se proyectan hacia otras esferas de acción: la educación, la política, la cultura, entre otros. A lo largo de la historia de nuestro país encontramos mutuales, asociaciones civiles, cooperativas de trabajo, cooperadoras, grupos autoconvocados (con o sin persona jurídica), asambleas barriales, movimientos de trabajadores desocupados (piqueteros), trabajadores organizados para recuperar su trabajo (fábricas y empresas recuperadas). Algunas de estas formas tienen tradición histórica larga aunque puedan ir cambiando sus contenidos y orientaciones. Otras 
tienen tradiciones más cortas en el tiempo pero profundas en el contexto argentino actual: la forma organizativa asamblea barrial, por ejemplo. Algunas de ellas han dado lugar a una educación política y ciudadana de muchos participantes que, a partir de su involucramiento en discusiones y acciones colectivas, han construido nuevos proyectos: huertas urbanas comunitarias, centros de lucha contra el trabajo esclavo, comedores barriales, centros culturales, participación en la recuperación de fábricas, entre otras experiencias. También las asambleas han sido lugares donde activistas y militantes nacidos en la década de 1950 1960 retomaron formas de participación política que habían dejado de lado durante la persecución de la dictadura, y que no habían vuelto a poner en práctica con esta convicción o fuerza, y crearon otras nuevas, vinculándose con activistas, militantes, vecinos y participantes mucho más jóvenes, que sostienen también una trayectoria fresca de experiencias colectivas (por ejemplo, los nacidos entre 1975 y 1982).

En este escrito, cuando hablamos de colectivos autoconvocados y autogestionados, nos referimos a formas asociativas de hacer y pensar que se orientan hacia el ejercicio de la justicia, igualdad, equidad, paridad en la toma de decisiones, libertad para ejercer el pensamiento sin dogmas y construcción de una forma de verdad que contemple las disonancias, alteridades y tensiones que se alojan en el proyecto mismo. Estas orientaciones se verifican tanto hacia su interior como hacia el contexto en que operan. De esta manera, nos referimos a colectivos que construyen un régimen de sentido democrático tal que Castoriadis (1997) denomina autonomía como proyecto y por tanto: a) permanecen abiertos a la interrogación de los significados que orientan su práctica, sobre la base de su referencia a unos valores de igualdad, justicia, equidad, libertad y búsqueda de la verdad; $b$ ) proponen un modo de comunicación franco (vinculado a lo que se identifica como formas discursivas ligadas a la parrhesía, traduciéndola libremente como «hablar con el corazón en la mano»); c) permiten la construcción de la ley grupal en forma colectiva, asumiendo que todos los que participan tienen paridad en el debate que permitirá construir esa ley.

El material que presentaremos para consideración es sobre estas organizaciones colectivas 
que buscan que la democracia tenga sentido, se llene de significancia y se impregne de posibilidad. Nos proponemos examinarlo en clave de aperturas o clausuras a pensarse, ya que, parafraseando a Castoriadis (1990), decimos que al proyecto de autonomía no se arriba ya que nunca se completa. Está en interrogación continua sobre sus posibilidades, efectos, regímenes de significación, y esta situación es posible porque se piensa a sí mismo como una construcción en marcha. Así, hemos querido interrogarnos sobre la reflexión deliberada como práctica sistemática de análisis de nuestras creaciones institucionales, en tanto colectivos de autogestión en el encuadre del proyecto de autonomía.

UN PUNTO DE PARTIDA SOBRE LA REFLEXIÓN DELIBERADA Y LA DELIBERACIÓN REFLEXIVA

Para pensar sobre las producciones organizacionales de nuestros colectivos hemos creado durante el año 2012 la Mesa Colectiva de Trabajo. En ella hemos indagado sobre las relaciones y diferencias entre lo que Castoriadis propone como reflexión deliberada (más detallado en la sección siguiente) y lo que varios de nosotros conocemos como práctica más habitual: la deliberación reflexiva. Esta última se refiere a la posibilidad de los grupos autogestionados en que participamos de poner en discusión las ideas orientadoras y las acciones que damos para llevarlas a cabo, y las relaciones que establecemos internamente, con otros grupos, y el contexto al realizarlas. Sin embargo, en nuestro trabajo juntos hemos ido identificando que no es tan común sostener una práctica de reflexión deliberada colectiva que revise críticamente las orientaciones que nuestros proyectos sustentan, las cadenas de asociaciones (relevos y eslabones, en la lengua de Castoriadis 2004: 109) que proveen significación, y las rupturas o momentos de inflexión que tal vez serían indicadores de una investidura-desinvestidura de la libido colectiva, de procesos de descalificación y recalificación, siguiendo a nuestro autor.

\section{REFLEXIÓN DELIBERADA}

Los términos «reflexión»y «deliberada», asociados entre sí, han sido analizados por 
Castoriadis en varias de sus publicaciones, entrevistas, conferencias y seminarios (por ejemplo, en sus escritos de los Seminarios 1986-87, publicados en 2004 en español con el título de Sujeto y verdad en el mundo histórico social, o en su larga reflexión sobre el «Estado del sujeto hoy», publicada en español en 1992). Uno de los aspectos de la reflexión deliberada refiere a su vinculación con la democracia como régimen de sentido (Castoriadis 1997). Dicha expresión apunta, como ya señalamos, a la posibilidad de un proyecto colectivo de autointerrogarse, reconociéndose como productor de su ley colectiva. A la vez, con posibilidad de deliberadamente tomar posición en relación con las orientaciones que guían su práctica. De esta manera la norma no es creación extrasocial sino son los seres humanos en sus relaciones quienes construyen regímenes de práctica y sentido (Castoriadis 2007). Así, «Nuestra tradición creó también la libertad y la responsabilidad de elegir. Elegir es un acto político que está en la base de la filosofía propiamente dicha. Para ingresar en la actividad filosófica hay que elegir el pensamiento frente a la revelación, la interrogación ilimitada frente a la aceptación ciega de lo que ha sido heredado» (Castoriadis 2002a: 142).

Uno de los ángulos que toma Castoriadis para abordar su discusión sobre las relaciones entre «reflexión» y «deliberada» es el de las relaciones psique-sociedad. ${ }^{2}$ Castoriadis se interroga de qué es capaz la psique humana y qué de lo propuesto por Freud puede revisarse críticamente para pensar nuevamente las relaciones psique-sociedad. A sus preguntas responde que la potencia de la subjetividad humana se sitúa más bien en una capacidad única entre todas las especies: la capacidad de imaginación radical. Entre otros aspectos, Castoriadis señala que, por ejemplo, el lenguaje se desarrolla precisamente por esta posibilidad únicamente humana de simbolizar a partir de imaginar en procesos metonímicos, metafóricos, de representación, de creación de formas y figuras, entre otras capacidades. Imaginar nos permite, entre otras cosas, pensarnos reflexivamente: vernos como «otro» a ser pensado. Sin esa capacidad de imaginarnos otros no podríamos producir autorreflexión, por ejemplo (Castoriadis 1997, 2002b).

Paradójicamente, la filosofía heredada ha puesto más acento en que la capacidad de 
reflexión es un pensamiento que continuamente sopesa y calcula, y que en algunas versiones de la filosofía, además, tiende a «controlar las pasiones», los deseos, o la imaginación, inclusive (Castoriadis 2004, 2007). Castoriadis insiste en mostrarnos que la reflexión humana está permanentemente en flujo, trabaja por asociación, construye representaciones y las construye a partir del deseo y de la carga libidinal. Ha denominado magmática a esta capacidad. De esta manera, Castoriadis postula que la subjetividad humana tiene como condiciones de su existencia el hecho de crear formas y figuras (crear representaciones, incluso la representación de sí mismo y para sí mismo), de operar en construcciones afectivas y de estar también en la corriente del deseo (Castoriadis 2005).

\section{REFLEXIÓN Y VOLUNTAD}

Por estos motivos, tomamos de Castoriadis la insistencia en señalar que la subjetividad humana con capacidad reflexiva se aloja en sus capacidades psíquicas magmáticas. La construcción de subjetividad, además, puede operar a partir de la voluntad (que él denomina actividad deliberada), en el sentido de tener la posibilidad de dirigir su voluntad a un objeto de pensamiento, sin perderlo de vista e incluirlo en su cadena de asociaciones. Nuevamente sería un sentido ampliatorio de la idea de voluntad, y no restrictivo; en sus palabras:

[El pensamiento] está sostenido por un vector de voluntad, de deliberación, que a través de todos los meandros y todas las encrucijadas del laberinto, no le deja perder de vista su o sus objetos [...]. Cuando se explora una cuestión puede producirse un cambio o una modificación: surge espontáneamente una representación que hará ver otro aspecto de la cuestión y hará así que se dibuje otro objeto, más importante que el del comienzo (2004: 108).

El tipo de subjetividad que intenta describir es una capacidad para «hacer entrar en los relevos que condicionan sus actos los resultados de su proceso de reflexión» (2004: 109). La voluntad sobre la que este autor nos propone pensar es el esfuerzo que como humanos 
podemos hacer para incluir dentro del campo de reflexión, deliberadamente, objetos que se presentan ante nosotros, precisamente por la capacidad fundamental del ser humano: la capacidad de imaginar.

Una de las conclusiones a las que el autor arriba es acerca de las determinaciones y las aperturas posibles de la psique. Nos indica que la subjetividad humana contiene a su vez la posibilidad de «quedar presa» de sus determinaciones como de abrir su voluntad a reflexiones que emplacen nuevas construcciones. Este sería el sentido para Castoriadis de reflexión deliberada: aquella que nos permite, como subjetividad humana individual y colectiva, construir proyectos precisamente porque podemos imaginar lo distinto, lo que hoy no está o no existe o no es. Y también imaginar algo que se constituya por otra cosa, es decir, crear una representación. Apoyándose en el psicoanálisis, indica que esta capacidad de producir representaciones se liga con la capacidad de la psique de sublimar: de hacer algo diferente o poner algo distinto, rompiendo de alguna manera asociaciones viejas y creando un espacio para la producción de algo diferente, tesis que desarrolla con diferentes ejemplos histórico-sociales, tanto de la sociedad contemporánea como de sociedades más antiguas (Castoriadis 1980, 2004, 2006, 2007). En este sentido, la capacidad de crear es sublimatoria y es posible también por la existencia de energía disponible. La energía psíquica es la que podría pensarse como motor de los procesos de descalificación o de recalificación de objetos pulsionales (que pueden ser objetos reales, ideas, representaciones). Los objetos a los que dirigimos nuestra energía conforman así tejidos de significación porque se invisten (se tornan importantes, podríamos decir).

La capacidad de la psique de modificar la investidura se denomina labilidad y es una característica humana universal. Sin embargo, la labilidad está codificada en cada entramado histórico-social específico de modos particulares. Así, la capacidad de investir es universal mientras que los contenidos de la investidura son contextualmente situados. Por ejemplo, existen sociedades (a nivel general, en el sentido que Castoriadis da al histórico-social) e instituciones (a nivel particular de cada histórico-social) donde la 
posibilidad de abrir la interrogación sobre los contenidos y significados que se privilegian está instituida, y otras en las que no es posible. En las sociedades donde sea posible dicha interrogación estaremos en presencia de una orientación hacia la autonomía y esta orientación está fundada, en parte, en la posibilidad de que se establezcan relaciones entre lo consciente y lo inconsciente, tales que «un sujeto pueda decir de forma fundada: esto es verdadero y este es mi deseo. Bajo reserva de agregar, por cierto: «y no me voy a conformar con eso» (2004: 143).

\section{FORMAS QUE ADOPTA NUESTRO TRABAJO COLECTIVO}

Durante 2008-2011 la Asociación INCLUIR trabajó junto a varios grupos autoorganizados, autoconvocados y autogestionados. El enfoque metodológico durante este proceso se orientó por la etnografía y la sociolingüística de la interacción (Heras 1993, 1995, 2009) y desde una perspectiva interdisciplinaria. Este equipo se había propuesto generar vínculos a través de diferentes formas de producción de conocimiento: un proyecto de investigación acción, tres encuentros abiertos colectivos, varias mesas de debate, participación en diversos foros, integración del consejo editorial de la revista de Economía Social junto a varias organizaciones, estancias en diversas localidades de Argentina para documentar organizaciones autogestionadas en distintas provincias de Argentina, entre otros. A partir de estas formas de conocimiento se fue produciendo una gran cantidad de información y algunos análisis específicos sobre cuestiones de relevancia para los grupos autogestionados. $^{3}$

En enero de 2012 la Asociación INCLUIR tomó la iniciativa de invitar a algunos colectivos en particular a formar una Mesa de trabajo ${ }^{4}$. Aceptar la invitación para cada grupo implicaba estar dispuestos a vernos como grupo (Mesa Colectiva) y a la vez vernos cada uno en y desde nuestro grupo (es decir, analizar nuestros grupos de origen), abriéndonos a la mirada de los otros participantes. Se hizo operativa en forma de Mesa, lo cual quiere decir que cada colectivo designó a quien iba a participar y ocupar el lugar alrededor de la 
Mesa. Se trata de un espacio de grupo pequeño (máximo 15 personas).

Como Mesa Colectiva, hasta ahora:

- realizamos una presentación en el marco del Seminario «El proyecto de autonomía hoy» (EPAH, que tiene su sede en México y está coordinado por Dolores Camacho y Rafael Miranda) para comentar nuestra forma de trabajo, recibir comentarios críticos constructivos, y producir una reflexión apoyada en la mirada de otros externos;

- identificamos preguntas-clave para cada colectivo de trabajo, como una forma de distinguir qué aspectos deseamos cada uno entender mejor de nuestra práctica;

- compartimos, interrogamos, indagamos, interpretamos y analizamos información a partir de registros en distintos soportes para comenzar a responder dichas preguntas;

- vimos videos e intercambiamos lecturas que se realizan tanto con antelación a cada jornada como durante la jornada de trabajo de la Mesa;

- generamos nuevos interrogantes que surgen de nuestros análisis;

- produjimos nuevos registros a partir de observaciones del quehacer de los grupos autogestionados para intentar responder a los interrogantes planteados;

- nos propusimos escribir esta primera producción colectiva que de cuenta de este proceso y de algunas de las ideas generadas.

Hasta la escritura de este artículo, en todas las reuniones de la Mesa se ha propuesto la coordinación de miembros de la institución convocante (INCLUIR), dado que aún nos estamos conociendo. Como INCLUIR participa al mismo tiempo como organización convocante del espacio y como organización que se mira a través de los ojos de los otros, esa coordinación es rotativa y compartida. Así, los cinco miembros que asisten a la mesa por INCLUIR desdoblan su participación: mientras 2 ó 3 de ellos actúan como coordinadores de la actividad de la mesa, los otros 2 ó 3 lo hacen en su función de miembros de INCLUIR como organización participante. 


\section{LA MESA DE TRABAJO COLECTIVA Y LA PRODUCCIÓN DE ESTE ESCRITO}

Nuestro escrito fue elaborado por once autores/as y colaboradores/as que intercambiamos nuestras producciones, ideas, preguntas, comentarios críticos, de acuerdo con nuestro horizonte de sentido, partiendo de suponer que éste siempre puede extenderse (Gadamer 1995, 2005). Para ello partimos de tomar herramientas en común y nos propusimos integrar también algunas distintas, producto de nuestras diferencias significativas existenciales. Un factor que tuvo peso en esta escritura colectiva fue el de las preferencias diferentes de cada uno por soportes y formatos para expresar ideas. Por ejemplo, algunos elaboraron a través de la fotografía como método de conocimiento, otros a través de lo escrito, otros por fin también tomaron lo audiovisual y lo oral, lo dramático y lo gestual, y sobre eso, pensaron, dialogaron y corrigieron, es decir, reenfocaron. De esta manera, hemos consultado nuestros archivos de audios, videos, fotografías, escritos (observaciones, entrevistas, actas, intercambios de mail, notas sobre las organizaciones publicadas en medios periodísticos, etc.), resúmenes de trabajo en soportes multimedia o mixtos, entre los más importantes.

Nuestro pensamiento se produjo en distintas instancias. Una de ellas fue el intercambio acerca de cada uno de los colectivos que participan en esta experiencia. A partir de esta primera instancia comenzamos la Mesa Colectiva de Trabajo a la que asistimos entre diez y catorce personas en forma regular (una vez por mes). Para cada encuentro planificamos dispositivos específicos que nos permiten analizar nuestro propio colectivo como los demás que integran la mesa. Por ejemplo: lectura y escucha; lectura en voz alta y discusión posterior; trabajo sobre registros (escritos o audiovisuales) que incluyen a veces cierta teatralización o recreación de observaciones registradas para su mayor comprensión; trabajo sobre materiales escritos por otros autores y posterior intercambio; visualización de cortos o segmentos de documentales, entre otros. Por fin, otras instancias propuestas han sido las situaciones de trabajo individuales o en grupos más pequeños que van surgiendo por las necesidades de cada uno de pensar solo o con otros. 
Además, hemos generado un dispositivo «de memoria colectiva» que se va conformando entre todos en la medida en que se avanza en la producción de registros y análisis. Para esto se han generado reservorios de materiales en soportes variados que todos podemos consultar (digital, papel, materiales mixtos tales como papeles afiche o papelógrafos con técnicas de facilitación gráfica también mixtas como combinaciones de collages, dibujos, conceptos o escrituras realizadas con fibrones o lápices de colores). El reservorio digital fue desarrollado utilizando software libre (drupal) y se puede acceder a él a través de una clave otorgada a cada integrante de la mesa.

\section{METODOLOGÍA}

Los análisis presentados en este escrito se orientan de manera general por entender:

- cómo se continúa aprendiendo la autogestión en nuestros colectivos;

- cuáles de los dispositivos institucionales que vamos generando corresponden con la autonomía como proyecto (y cuáles podrían estar en tensión con estas orientaciones);

- cuáles son nuevas creaciones que ese aprendizaje habilita y cómo interpretarlas en relación con la autonomía como proyecto;

- cómo se conjuga la diversidad entre los miembros para hacer algo colectivo en cada grupo.

Tomando en cuenta lo anterior, para este escrito nos hemos preguntado específicamente:

1. ¿Cuáles pueden ser distinciones posibles entre reflexión deliberada y deliberación reflexiva al analizar la práctica de la autogestión? ¿Qué puede aportar distinguirlas para la práctica y el avance teórico conceptual sobre la autogestión como proyecto de autonomía?

2. ¿De qué forma se construye la deliberación y la reflexión en los momentos de 
trabajo específicos (sea en cada colectivo de autogestión o en el espacio de nuestra mesa colectiva)?

3. Vinculado a la forma de construcción de la deliberación y la reflexión ¿qué de lo que ocurre puede pensarse desde la idea de espejo? ¿Cuáles son las formas que adoptan en el lenguaje y en qué soportes es esto visible (oral, visual, escrito, etc.)?

\section{ANÁLISIS SOBRE LOS COLECTIVOS AUTOGESTIONADOS Y EN SUS VOCES}

ANÁLISIS SOBRE EL COMEDOR A CIELO ABIERTO «EL GOMERO» PRODUCIDO POR PARTICIPANTES DE ESE COLECTIVO

Presentamos a continuación dos relatos analíticos diferentes de integrantes del comedor sobre la reflexión, la deliberación y la reflexión deliberada que, además, han sido trabajados también con fotografías por parte de una tercera integrante del comedor (fig. 1). A través de estos relatos queremos enfocarnos en las tres preguntas formuladas más arriba, tomando como punto de apoyo lo que elaboran los participantes de este proyecto en particular, y mostrando también algunos cambios identificados a través del tiempo por ellos mismos.

Figura 1. Bandera del Comedor El Gomero

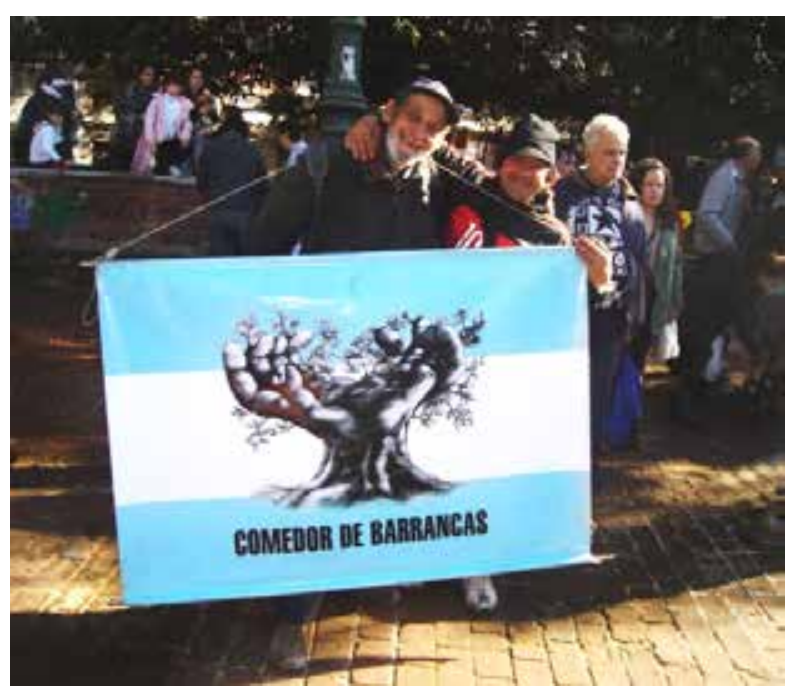


El comedor nació como una expresión de solidaridad hacia quienes estaban decididamente mal, en un momento determinado y en respuesta a una emergencia social (año 2002). El plato de comida no era otra cosa que una excusa para estar cerca de quienes sufrían más duramente la crisis de entonces y eso nos convocaba a reunirnos y compartir angustias (fig. 2). En forma totalmente desordenada, casi sin planes o proyectos que no sean simplemente esos: estar cerca y darles el apoyo que pudiéramos brindar quienes estábamos en una situación circunstancialmente mejor. Sin embargo, esa tarea requería cierta «organización» para poder llevarla adelante (juntar víveres, cocinar, reunir vajilla, ropas, etc.): únicamente lo material del hecho de servir una comida era lo que nos obligaba a darnos una suerte de organización. Lo demás, que era lo principal, se realizaba «como viniera». Cada uno le daba la carga que tenía en su interior.

Figura 2. La preparación de la comida

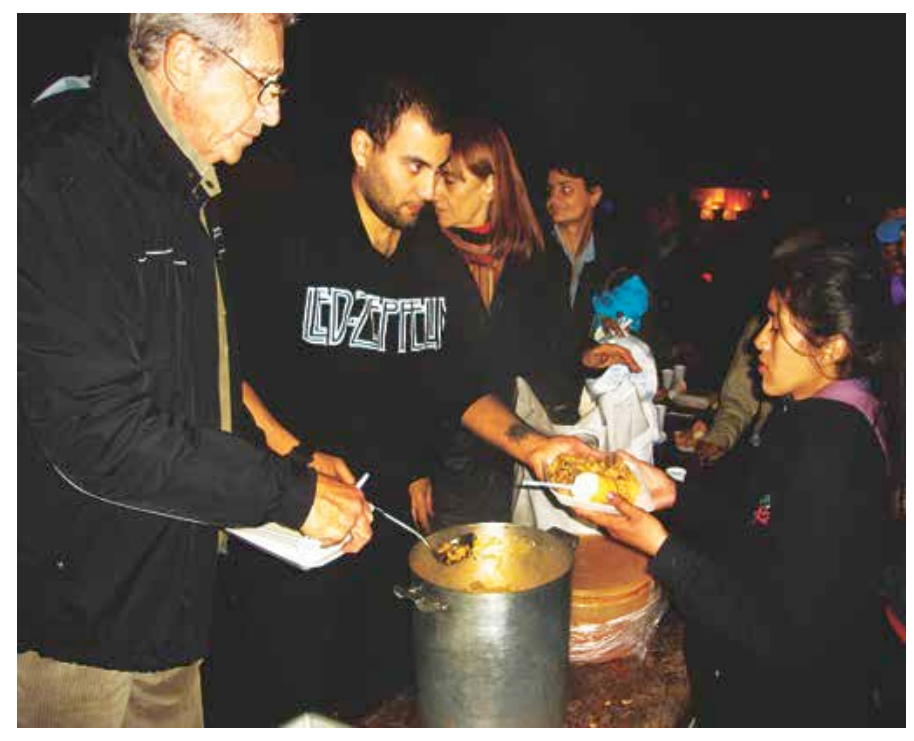

En los primeros voluntarios la motivación era de cada uno, con un solo eje en común: ser 
solidarios con cartoneros, gente de la calle y familias en estado de extrema pobreza (fig. 3). Había quienes eran movilizados por un sentimiento de piedad para con los más débiles. Otros, que instaban a la gente a reaccionar frente a tanta injusticia. No faltaban los que querían dar lecciones de cómo debían reinsertarse en los cánones que imponía la sociedad «civilizada». Entre nosotros estaban también los que querían hacer la revolución con ese ejército despatarrado de soldados destruidos por la pobreza y los que no tenían otra intencionalidad que la de cumplir con una tarea asistencial de emergencia por el tiempo que ella durara y que se esperaba que fuera breve. El temor de los más era que esa «asistencialidad» se transformara en un fin en sí mismo. En casi todos había un espíritu colonizador o misional, poniéndonos en el rol de dueños de la verdad, dispuestos a «enseñarles» las bondades de pertenecer a una sociedad, que era la nuestra, con acceso a la educación, al trabajo, a una vivienda propia, etcétera. Lo que nunca pudimos descifrar es qué se encerraba en ese «etcétera» y que quizás ahí estaba lo verdaderamente importante.

De toda esta mezcla extraña nace el Comedor de Barrancas. Me animaría a decir que el Comedor El Gomero fue y es el resultado de seguir los acontecimientos que le cayeron encima. Sería algo así como un lugar en la calle para gente en situación de calle. Y las reglas de la calle no son muy claras. Jamás se nos ocurrió que deberíamos tener un lugar en el mundo que no fuera ese lugar... en la calle... o al lado de la calle. Estuvimos casi siempre detrás de los acontecimientos que nos marcaba la realidad. Un día la expulsión de los cartoneros de Barrancas, otro, las «apretadas» (término de uso coloquial que se refiere a prácticas de amedrentamiento policial) de la policía y de personas extrañas (disfrazadas de indigentes) que venían a provocarnos. Ahora la pérdida del lugar para el apoyo escolar y la consecuente búsqueda de un lugar para continuarlo... y muchas cosas más que ocurrieron en el medio que me llevan a pensar que el comedor, más que un proyecto, es un resultado incierto que nos deparó el destino. 
Figura 3. Confección de frazadas para los asistentes al comedor

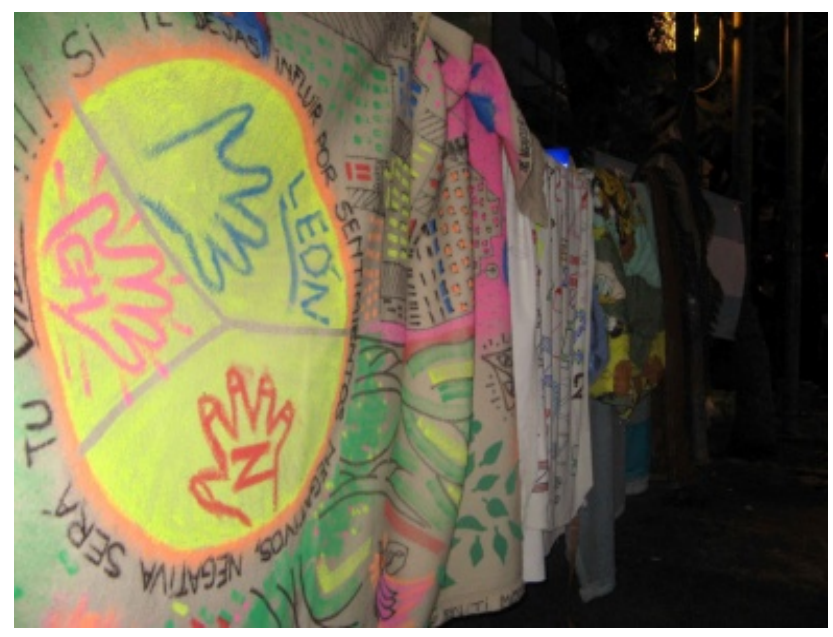

SEGUNDO RELATO. APOYO ESCOLAR

La toma de registros de todo lo significativo que transcurrió en el último año 2011 por parte de nuestro grupo (Comedor El Gomero) y de INCLUIR implicó tener en cuenta correos electrónicos, registros fotográficos, notas descriptivas. Esta suma de posibilidades propició nuevos pensamientos. Este ejercicio habilitó también nuevas posiciones, rechazos, a veces matices sobre los temas tratados. Fijó puntos de apoyo que por sobre el dato meramente histórico, dejan la puerta abierta a nuevas revisitas, sin plazos ni garantías de revalidación. Construyó puentes. Sin embargo, no deberíamos confiarnos en la solidez de los materiales a desplegar de una orilla a la otra: la reflexión, en su ir y venir, en la cadena de rebotes, puede arrojar indicaciones frágiles, cortas, efímeras. Solamente podemos afirmar que existen puntos de encuentro e incidencias mutuas entre las deliberaciones que se suscitan en el ámbito de la mesa de trabajo y las reflexiones que producen las organizaciones en su interior, en el andar cotidiano y en los espacios habilitados de evaluación y proyección de ese andar. Esas reflexiones se construyen tanto alrededor de la tarea concreta (en este sentido sería una deliberación para reflexionar sobre lo hecho) como de las orientaciones o los significados que se construyen sobre y en esa práctica (como una brecha en nuestro 
pensamiento como colectivo) lo cual nos permite pensar que se estaría en el marco de una reflexión deliberada.

Dentro del colectivo del comedor está habilitada la posibilidad de crear grupos autoconvocados y se forman para aspectos específicos. Uno de ellos fue el de apoyo escolar, que se gestó durante varios años (2004-2009) como actividades relacionadas con lo educativo en general, y se organizó más específicamente pensado como apoyo a la escuela desde 2010 (fig. 4).

Figura 4. Apoyo escolar

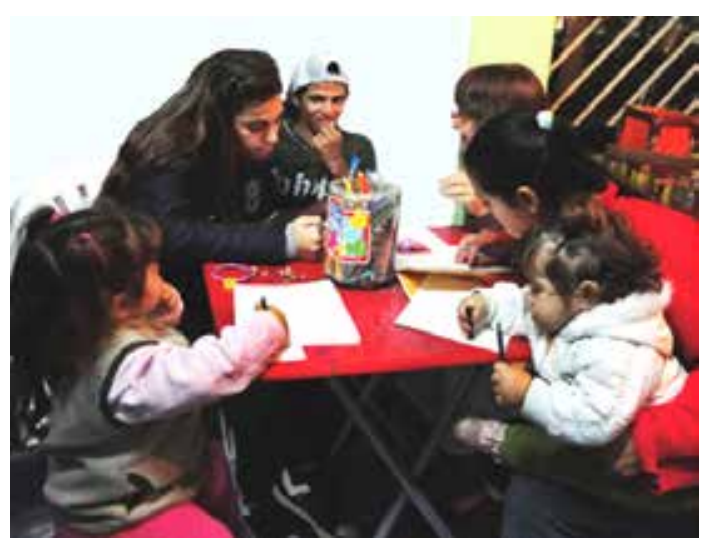

Si bien antes de esa fecha existían actividades educativas, recreativas y artísticas en el comedor, que continúan existiendo, el grupo pensado para trabajar sobre aspectos educativos vinculados a la escolarización surge en 2010. Este grupo decidió autoconvocarse periódicamente y, además, no perderse el espacio de reflexión sobre sus objetivos, posibilidades, problemas recurrentes y organización de actividades (fig. 5). Esta posibilidad se produjo en 2011 en forma sistemática porque la ofrecieron los voluntarios de INCLUIR para acompañar nuestro proceso. A través de observar nuestra práctica concreta por medio de nuestras reflexiones, fotografías y registros escritos, pudimos cuestionarnos sobre nuestro quehacer. 
Figura 5. Reuniones de trabajo

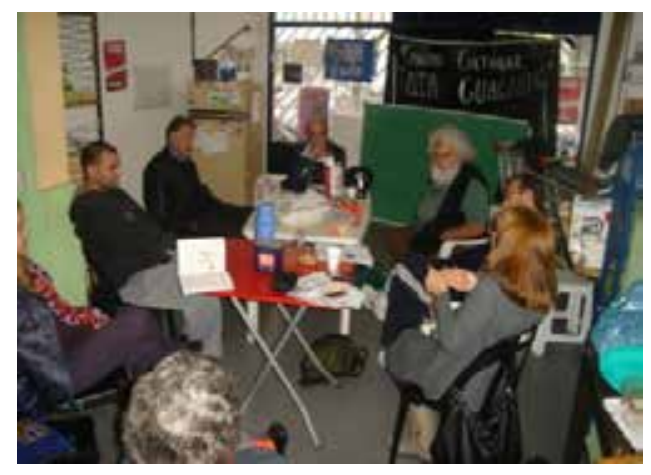

Nos posicionamos así en que el trabajo apunta más a desarrollar el espíritu crítico y conocer diferentes técnicas de expresión para los niños o jóvenes que concurren al apoyo y así probablemente encontrarnos con el deseo de ellos. Empezamos entonces con una reflexión sobre la tarea concreta, más cercana a una evaluación de lo propuesto y lo logrado, y a revisar la orientación sobre la que se fundó este espacio de trabajo. Llegamos así a pensarnos en el marco de la educación popular. A través de este primer posicionamiento, y en diálogo con otra organización, se consiguió material para alfabetización de adultos. Allí se produjo otro nuevo reposicionamiento, ya que los voluntarios del apoyo escolar aprendimos que existe un enfoque educativo que se concentra no solo en alfabetizar sino en pensar que la alfabetización podría permitir reflexionar críticamente sobre la realidad. Estos cambios de posicionamiento ocurrieron en encuentros concretos en los que se producían grietas (en el pensamiento de los voluntarios del comedor) a partir de contrastar nuestras propias ideas con las de otros (de INCLUIR en este caso) o con nuestras propias ideas según quedaban registradas y podíamos revisitarlas.

A las dos semanas de estas reflexiones en conjunto se evaluó la puesta en práctica, lo planificado y las circunstancias de los dos últimos encuentros del apoyo. Al volver a tomar lo hecho para pensarlo, surgió en el grupo la idea de que el proceso de trabajo en apoyo escolar es de largo plazo. Con este nuevo horizonte de sentido, la tarea cobró otra 
dimensión, ya que fue produciéndose una revisión sobre los modos de pensar las relaciones entre quienes concurren al apoyo como «alumnos» y quienes están allí en tarea docente. Estas reflexiones a su vez se vinculan con otros procesos de pensamiento sobre quiénes son/somos los que estamos en el comedor. Están los «que asisten» al comedor (van a comer, a recibir ropa, a participar de los espacios de apoyo escolar) y los «voluntarios». Y entre estos dos grupos se presentan situaciones a veces tensas e incluso violentas (para un análisis de este aspecto en particular véase Heras 2012). Tomando en cuenta estas cuestiones se analizaron las situaciones y se revisó la posibilidad de variar las formas de vinculación, poniendo acento en escuchar la voz de quienes participan como «asistentes». Se tomó entonces esta perspectiva para el trabajo en apoyo escolar y para el momento del comedor, donde se comienza a instalar una práctica de asamblea a micrófono abierto.

Este pensamiento fue guiado por la preocupación que existe en los voluntarios del comedor de no repetir una relación de «asistencia» sino provocar la posibilidad de tomas conjuntas de decisiones. Los riesgos de la reflexión deliberada sobrevuelan las meditaciones, somos conscientes de que más allá de entender, de aprender del otro y saber más de nosotros mismos, está el derecho humano a ser escuchado, que todo lo que hacemos no tenga mayor sentido que reforzar, en algunos casos devolver, la condición reflexiva y la voz que la desigualdad de posibilidades apropió: ese se transforma en el eje de la tarea y se comienza a perfilar más fuertemente como orientación de toda la labor de los voluntarios del comedor. En este sentido se puede ver cómo se tienden esos puentes de los que hablábamos al principio entre deliberar (sobre lo hecho) y cuestionar las fundaciones de la tarea que se realiza. Se señala que en ese camino ocurrieron situaciones de discusión (a veces tensas) entre los voluntarios del comedor. Esta discusión continuó y se acordaron algunas formas de trabajo nuevas a partir de tales intervenciones y diálogos. Estamos en proceso. La reflexión deliberada emerge alrededor del diálogo, es el entramado dialógico, multilógico, que posibilita la intervención en el cambio que nos convoca. La posibilidad y la decisión de pensar nuestro devenir, el nosotros, si existe, y hasta dónde llega, quiénes somos, si vale la pena el compromiso, si las urgencias no nos convirtieron en mandatarios inconscientes de 
esos otros que nos condicionan, si el objetivo merece concesión.

\title{
PENSANDO LOS DOS RELATOS EN CONJUNTO
}

Una aproximación a estos relatos escritos y fotografiados nos permite comprender distintas lógicas en juego en la misma organización. En el primero se detallan los orígenes del grupo, las situaciones que exigían una gestión propia y que además se enmarcaban en la pregunta por la (in)justicia, la (des)igualdad, la diferencia producto de políticas económicas sostenidas en Argentina. Aparece fuertemente la conexión entre una tarea que debe ser resuelta y la organización (definida «como viniera») para producirla. En el segundo relato aparece con igual fuerza la idea de revisar lo hecho y encontrar la grieta por donde colar algo diferente. Estas distintas visiones, en palabras de uno de los miembros de este mismo grupo, nos permiten poner de relieve que

\begin{abstract}
Organizar algo que tiene que ver con el estar cerca implica reflexionar sobre puntos de conexión inmateriales, complejos, simbólicos que se requieren para organizar tareas de materialidad ausente, materialidad que las ollas y los alimentos sí le aportan a la cena. Tal vez la expresión «a como venga» da cuenta de que las distintas formas de pensar y sentir de los voluntarios no logran cruzarse en un ámbito de reflexión. No parece haber capacidad (¿o voluntad?) explícita de hacerlo, no existe como acto deliberado el hallazgo e identificación de ese «material» abstracto que nos lleve (unos a otros) hacia los otros voluntarios y fundamentalmente hacia los «asistidos» (en forma organizada), que permita encaminar la reflexión sobre este aspecto específico: acercarse al otro y que de ahí (de esa abstracción que llamamos antes el estar cerca), surjan acciones concretas. Sería ir de lo abstracto a lo material. (Intercambio por correo electrónico de MJ, integrante del Gomero)
\end{abstract}

También en el segundo relato aparecen aspectos que cabe destacar:

Si tuviera que elegir una grieta, asumida por pocos (por lo desafiante), es que el apoyo en su carácter de «escolar» aplica poco. Eso que mencionaba en mi escrito: la invitación a 
reflexionar, a pensar nuestra actividad «escolar» nos permitía reconocer la urgencia de otro tipo de apoyo, asumir que uno de los condicionamientos que recaía sobre los niños y adolescentes con quienes tratábamos era su no acceso a la escolaridad. Creo que no se asume esa situación porque nos paraliza la idea de diseñar y llevar adelante una actividad diferente de la educación escolarizada que está en nuestros huesos. Nos resulta demasiado extraña. Como decimos más adelante en el escrito, «se clausura la posibilidad de debatir en profundidad las significaciones imaginarias que están guiando este proyecto» (Intercambio por correo electrónico de MJ, integrante del Gomero).

REFLEXIÓN, DELIBERACIÓN: ¿TENSIÓN ENTRE UNA Y OTRA? UNA MIRADA A LOS COLECTIVOS AUTOGESTIONADOS

A continuación incluiremos el análisis sobre los intercambios que suceden dentro de los colectivos con el objetivo de problematizar sobre las diferencias entre deliberación reflexiva y reflexión deliberada. Se presentan ejemplos documentados en distintos grupos ya que, por nuestro enfoque etnográfico, tenemos la posibilidad de revisar registros de tiempo largo. En cada uno de ellos se intenta mostrar el punto donde se clausura lo que podría convertirse en reflexión deliberada.

PRIMER RELATO. APORTES AL GRUPO

Uno de los colectivos que participan en la mesa acordó escribir, a principios del año 2012, sobre los posibles aportes que cada integrante se proponía hacer durante el siguiente semestre. El contexto que había llevado a esta propuesta se resume apretadamente: en 2010 una integrante del grupo había decidido alejarse (y el grupo también le había pedido que renunciara) por no interesarle el modelo de funcionamiento autogestionado; en 2011 dos integrantes se mudaron a vivir a otras provincias y a pesar de haber expresado sus deseos de participar en la institución, no pudieron realizarlo; otra integrante necesitó tomarse licencia ante una serie de dramáticas situaciones de salud en su familia y una cuarta integrante que se había asociado y prometía incorporarse en la dinámica cotidiana de trabajo postergaba esa 
decisión por cuarta vez. Por último, ese mismo año, otro integrante falleció inesperadamente.

La propuesta de revisar los aportes de cada miembro tenía el sentido explícito de analizar si quienes integraban activamente el grupo y la institución podían sostenerla, y también analizar cuáles eran comparativamente los aportes de cada integrante apuntando a poner en práctica un criterio de justicia, si bien de todos modos el colectivo entendía que no todos podían aportar en igual medida (ya que los aportes de trabajo eran voluntarios y las situaciones personales eran diferentes en cuanto a carga familiar, ingresos, etc.). Se intentaría luego comprender la relación entre lo comprometido y lo realizado para ver qué hacer en caso de que los compromisos mínimos no se pudieran cumplir -algo que ya había ocurrido anteriormente- y si esto se repetía, rediseñar eventualmente la estructura institucional en función de la energía disponible. Esto podía llevar a tomar la decisión de cerrar la institución tal como es ahora o modificarla hacia algo completamente diferente (por ejemplo, renunciando a la personalidad jurídica y evitando de este modo la obligación de realizar balances, llevar libros rubricados, soportar controles de los organismos fiscales, enfrentar el pago de un contador, etc.). Si bien el ejercicio parecía resultar adecuado para todos al ser propuesto, no se profundizó en dicho momento acerca del sentido que podía tener cerrar la institución o incluso qué consecuencias podía implicar realizar este ejercicio. Quizás pudo haberse aceptado como un modo de postergar decisiones. Los integrantes completaron una planilla que se propuso para que cada uno expresara sus posibilidades. Algunos listaron sus objetivos y acciones de manera detallada en tres páginas. Otros definieron sus compromisos en unas pocas frases. A los seis meses, cumplido el tiempo acordado para evaluar lo propuesto y lo hecho por cada uno y como grupo, se convocó a una reunión. Uno de los integrantes avisó un rato antes de la reunión que se había torcido un tobillo. Luego dos integrantes leyeron sus compromisos y sus metas cumplidas. A continuación otro integrante visiblemente angustiado compartió su sensación de ahogo por darse cuenta de que no iba a poder cumplir con las exigencias que implicaba el sostenimiento cotidiano de la organización y pidió una licencia en su participación en la comisión directiva. Por último, otro participante que también había tenido dificultades en cumplir con los compromisos asumidos por 
situaciones familiares dramáticas, tomó la angustia expresada por el anterior y planteó que daba para pensar que esta situación generara angustia y que eso le hacía ruido. El grupo debía poder contemplar las situaciones personales de todos los integrantes.

Luego de estos intercambios los demás integrantes no leyeron su respectivo informe sobre lo que habían realizado, sobre lo hecho o no hecho. En las semanas siguientes el responsable de convocar a las reuniones envió un mail con el orden del día de la siguiente reunión donde no incluyó como tema la finalización de este proceso. Uno de los que no leyeron su informe indicó que era necesario retomar la discusión. Se pudo completar la lectura de los planes en la reunión siguiente, a la que ya no asistió la integrante que pidió licencia, pero sí quien se había torcido el tobillo. No se realizaron casi comentarios sobre la situación que mostraban los informes. Se terminó planteando continuar el debate por mail a partir de una serie de preguntas que formularían dos de los integrantes.

Pareciera difícil o imposible en determinadas configuraciones grupales hablar «con el corazón en la mano», compartiendo los marcos de pensamiento y actuación personales y su relación con el cumplimiento de las normas que el mismo grupo se da para poder sostener el proceso colectivo y la estructura institucional. Tratando de analizar las causas, quizás se deba a que en 2005 este colectivo sufrió rupturas a partir de situaciones de reflexión deliberada o de la actitud parrhesiasta de algunos integrantes. Y en 2009 hubo situaciones de evaluación difíciles porque no todos los miembros entendían «evaluar la tarea» del mismo modo. Es posible comprender que hubiera cierto temor a disparar una nueva situación conflictiva por lo que esto pueda provocar. A nivel descriptivo podríamos decir que se clausura de diversos modos la posibilidad de debatir en profundidad las significaciones imaginarias que están guiando este proyecto.

¿Qué podría implicar la reflexión deliberada en este caso? a) disponer de la energía psíquica de los integrantes para romper con asociaciones de ideas y cadenas de significación que se fueron construyendo durante la historia grupal e imaginar algo distinto. 
O analizar alternativas para permitir condiciones de posibilidad del proyecto con una mayor creatividad; $b$ ) conversar sobre la posibilidad y los modos en que deberían convivir distintas orientaciones que de hecho existen dentro del colectivo, algunas más regidas por una lógica político partidaria y que valoran el fortalecimiento del Estado como medio de garantizar la justicia social y otras que se rigen por una orientación crítica de los partidos políticos y los dispositivos representativos de la democracia tradicional; c) revisar qué parámetros de evaluación, mecanismos de inclusión, reglas y dispositivos están y han estado haciendo difícil la inclusión de nuevos participantes o inciden y han incidido en las decisiones de abandonar la organización y en qué medida es así por la confrontación con las significaciones imaginarias sociales del contexto, por las características de personalidad de los integrantes o por otras cuestiones que podrían quizás modificarse; $d$ ) analizar cómo conciliar la necesidad de cada integrante de generar recursos para la supervivencia, y el tiempo que esto implica, con la posibilidad de destinar tiempo al trabajo voluntario en la organización o a la formulación de pedidos de financiamiento para lograr un trabajo rentado en la organización; $e$ ) analizar de modo realista hasta qué punto el colectivo puede contemplar y contener las situaciones personales de sus integrantes y de qué forma se concilia esta demanda con la posibilidad de que el colectivo logre sus metas.

SEGUNDO RELATO. CUANDO LA VOLUNTAD ¿NO ALCANZA?

Otro ejemplo proviene del trabajo realizado con una cooperativa con que se tiene relación cercana. En este caso se toman decisiones por impulso voluntarista acerca del volumen de tarea que se planifica llevar adelante definiendo metas imposibles de alcanzar con el trabajo aportado, que es voluntario y limitado (un promedio de 40 horas por mes de trabajo aportado por cada uno de 13 asociados, de las cuales 20 se dedican a las reuniones grupales para tomar decisiones). Esto sucede en forma recurrente. La frustración entonces gana al conjunto y muchos integrantes comienzan a retacear el trabajo especulando con que sus compañeros tampoco aportan. Sin embargo al discutir los objetivos varios integrantes defienden la necesidad de continuar con todos los objetivos inicialmente definidos, aunque 
eso los lleve a una parálisis, sin ningún argumento más que la supuesta libertad de sostener un deseo irrealizable. En este caso la reflexión deliberada podría llevarlos a comprender que los deseos parecen chocar con un límite fáctico y reevaluar hasta qué punto este límite opera como frustración del colectivo. A partir de esa reflexión quizás se habilite un proceso que permita abrir nuevas ventanas de significación continuando con algunos pocos de los objetivos iniciales o modificando los criterios de organización del colectivo, descentralizando la toma de algunas decisiones en personas o comisiones.

\section{TERCER RELATO. POSIBLES SOLUCIONES, ESCUCHAS PARCIALES}

En una reunión del colectivo que gestiona el comedor para gente en situación de calle se discute acerca de posibles alternativas para reemplazar el espacio de un local que era prestado por una agrupación política para llevar adelante la actividad de apoyo escolar. Cuatro integrantes defendían la idea, propuesta por otro voluntario, de comprar o conseguir un autobús y adecuarlo a esa actividad en lugar de intentar alquilar un local. Dos integrantes prácticamente no escuchaban esta propuesta, no podían siquiera considerarla como posible. No se dio el tiempo para comparar las opciones, sopesar ventajas y desventajas, sino que se cuestionó la alternativa rodante dando por hecho que no era posible, «no es lo mismo» fue el texto explícito. También se planteó «si pones un ómnibus en la plaza te lo van a ocupar»; «el costo de un garaje para estacionarlo es carísimo, porque necesitás al menos dos cocheras», «¿quién lo va a manejar? ». Sin embargo, argumentos similares a los que se esgrimían para cuestionar esta idea rodante se podían usar para cuestionar el local: el espacio del local era menor al del autobús (finalmente se aceptó gestionar el alquiler de un local de 2,5 m x 5 m con un subsuelo también pequeño, la mitad de la superficie de un autobús escolar grande). El costo para acceder al local era alto porque había que dejar un depósito, pagar la comisión de la inmobiliaria y dos meses por adelantado. Pero además el costo de la cochera, en caso que se decidiera guardarlo en un garaje, era la mitad de lo que implicaba un alquiler mensual. Y en cuanto a la posibilidad de intrusión, lo mismo podía ocurrir con el local, sobre todo porque la idea no era estacionar el 
autobús junto a la plaza.

Pasadas dos semanas, y una vez avanzada la negociación con la inmobiliaria, se analizó que quizás era necesario tramitar un acta constitutiva para poder firmar el contrato de alquiler, pero el costo de esta gestión era mayor aún, además que implicaba una demora de dos años. Luego habría que tramitar la habilitación municipal. Tampoco se dio lugar para evaluar las ventajas que representaba contar con el autobús, como, por ejemplo, trasladar a los chicos y familias a paseos, o viajar todos juntos los voluntarios hacia la isla del Tigre que uno de los voluntarios aportaba como sede de fin de semana, o trasladar donaciones, la posibilidad de vender el autobús en caso de que luego operativamente no funcionara como alternativa, la posibilidad de pintar el autobús reforzando la identidad del colectivo, etc. En este caso distintos modos de clausura directamente deshabilitaron la posibilidad de realizar una reflexión deliberada. En particular la voz grave y fuerte masculina que se contrapuso con cuatro voces femeninas que no se terminaron de confrontar, o el uso de un tono socarrón para referirse a la idea expresada, para finalmente cerrar la posibilidad con afirmaciones como «no: es imposible» o «es una locura». La reflexión deliberada ¿hubiera permitido analizar cuáles eran las significaciones imaginarias que estaban representadas para cada uno en las ideas de «local» y de «ómnibus» y comparar ventajas y desventajas de cada decisión? En este y en otros casos las voces de algunos integrantes del colectivo funcionan como «más autorizadas que otras» contradiciendo el espíritu igualitarista que explícitamente el grupo promueve.

Analizando los intercambios es posible afirmar que existe deliberación reflexiva. En todos estos grupos se opina y delibera, se analiza, compara, tipifica, evalúa, prioriza, decide y planifica sobre el hacer cotidiano partiendo de una serie de supuestos a veces personales y a veces grupales: cadenas de inferencias a partir de interpretaciones subjetivas informadas por un marco de pensamiento, una ideología, una orientación, unos valores o por las intenciones individuales - a veces ocultas y que se van develando con el tiempo- de cada integrante. Sin embargo, es menos frecuente que se reflexione sobre el sentido de lo que 
ocurre, es decir, precisamente sobre lo que condiciona esas inferencias e interpretaciones, el conjunto de ideas, paradigmas, valores e ideologías que inciden en cada definición y toma de posición. En la siguiente sección analizaremos dos conceptos que estamos identificando porque parecen operar en sentido de que esta reflexión se habilite.

\section{ABSTRACCIONES Y MATERIALIDADES QUE CONSTRUYEN REFLEXIÓN DELIBERADA}

En esta sección de corte netamente interpretativo proponemos un paso más acerca de dos conceptos que recorren nuestro trabajo: el espejo y las formas. Algunos participantes de la mesa colectiva identifican que este espacio les permite ver su propio proyecto a través de los ojos de otros. Esa situación hemos pasado a denominarla «espejo». Un aspecto destacado por varios participantes es que el «espejo» no se limita a ser una superficie que devuelve la imagen propia. La idea que circula es que el espejo no es pensado para reflejar coincidencias, sino diferencias. Qué se reconoce como propio y qué se reconoce como diferente; qué surge de ese reconocimiento de otras experiencias -y de otros- que no es enteramente igual a la nuestra. La reflexión, nada más subjetivo aun en un colectivo, si es potente y genuina, tal vez llegue hasta la mesa de los compañeros que aguardan en el territorio, para que en el juego infinito de los espejos enfrentados puedan decantar la práctica en pensamientos y conclusiones que retroalimentarán aquellas primeras reflexiones: algo cambió, una diferencia se suma al inventario de lo aprendido. En palabras de una participante de Diablo Mundo, y con respecto a las preguntas que su colectivo elige profundizar a partir del trabajo en la mesa:

Expresar en la mesa de trabajo colectivo el entramado y las anécdotas que suceden en el grupo abrió una invitación a la reflexión, que de alguna manera repercutió en nosotros. Por ejemplo: para pensar momentos de crecimiento y convocar a una reunión a colaboradores (en un contexto de crisis ya que una parte del grupo planteaba no continuar con el trabajo de la sala teatral por la energía que demandaba ${ }^{5}$ ), pudimos explicar con cuadros cómo funcionaba el espacio y las redes con las cuales se articulaba. Al comenzar a trabajar en la mesa y poner en palabras el entramado en el que nos encontramos inmersos, aparecieron 
muchas preguntas, algunas sin respuestas y otras que se van respondiendo sobre la marcha. Son estas:

- ¿ ¿Cómo se aprende el compromiso? ¿En qué medida se puede exigir compromiso a alguien que está haciendo su trabajo de forma voluntaria?

- ¿Cómo articulamos las diferencias y cómo nos incluimos todos en el proyecto colectivo?

- ¿Cómo articular las necesidades económicas de los integrantes del proyecto con las necesidades económicas del espacio?

En relación con estas notas y con dichos de los participantes de la mesa, estamos en condiciones de afirmar que, por un lado, la función espejo en el espacio de la mesa colectiva no se reduce al «a mí me pasa lo mismo que a usted» (que la mayoría de las veces quiere decir hablar de uno sin escuchar al otro), sino que se abre un nuevo eslabón en la cadena de pensarse: pensarse distinto y tal vez pensarse distante (ya que ver en el otro permite distanciarse y atenuar el temor al conflicto, por ejemplo). Por otro lado, que a un colectivo le pase lo mismo que a otro y puedan verse reflejados no es una simple anécdota. Pasa a ser una materialidad desde la cual interrogar ambos procesos, incluso los propios procesos de deliberación.

La construcción de reflexión y deliberación puede identificarse, entre otros modos posibles, a través de prestar atención detallada a las formas que asumen las interacciones entre diversos géneros textuales en los momentos de intercambio de mesa colectiva. Las formas textuales más recurrentes usadas por los participantes de la mesa colectiva, según las identificamos en nuestro material videograbado y luego transcrito en su totalidad, son:

1) Texto oral: palabra hablada

2) Texto escrito: palabra escrita

3) Textos visuales: imágenes fijas (uso de fotografías y dibujos) 
4) Textos audiovisuales: (fragmentos de registros realizados en los colectivos en formato audiovisual y cortos audiovisuales de animación)

5) Gestualidad: expresiones realizadas a través de la puesta en juego del cuerpo que sirven para enfatizar lo que se dice o bien para reemplazar el lenguaje verbal.

Seguimos las ideas de Bajtín, en particular para la oralidad y la escritura (1999: 4), quien propone pensar que «el uso de la lengua se lleva a cabo en forma de enunciados (orales y escritos) concretos y singulares, que pertenecen a los participantes de una u otra esfera de la praxis humana». Ese autor identifica además diversos tipos de enunciados a los cuales les da el nombre de «géneros discursivos»; éstos son «tipos relativamente estables de enunciados» (Bajtín 1999: 4), es decir, discursos estandarizados que circulan socialmente de acuerdo con convenciones más o menos rígidas y que pueden identificarse y diferenciarse unos de otros. Por ejemplo, un saludo, un cuento, un diálogo, una investigación científica, una nota periodística, son distintos tipos de géneros discursivos. Siguiendo esta idea, si se toma el texto oral como un tipo de texto general puesto en juego en la mesa colectiva, dentro de este tipo general, se pueden identificar los siguientes géneros discursivos: el diálogo, la presentación institucional (refiere a que se enuncia la voz de una institución como su historia oficial), la exposición, el intercambio con tono de debate reflexivo, el humor, el texto estético expresivo.

Así hemos querido destacar la importancia de generar soportes para nuestro pensamiento que se tornen útiles conceptualmente y que engarcen, por un lado la inmaterialidad de las representaciones (el valor del espejo para pensar la otredad y la diferencia, por ejemplo, en vez de insistir en su acepción de «reflexión de lo mismo» como concepto), como lo cercano a la materialidad de las formas (es decir, en qué soportes producimos pensamiento y comunicación, a través de qué géneros, con qué formatos estético-fonémicos, etc.). Creemos a partir de buscar estos engarces haber mostrado algunas condiciones en que debates y reflexiones se ponen en marcha y producen campos tal vez no previstos de pensamiento colectivo. A continuación procuraremos volver a los interrogantes de inicio 
para responder qué de lo trabajado hasta aquí nos permite construir algunas certezas y qué de lo presentado, por el contrario, es texto abierto.

\section{CONCLUSIONES Y PREGUNTAS NUEVAS}

Hemos planteado en la introducción que nos proponemos una lectura continua de la obra de Castoriadis para buscar, en su punto de intersección con la práctica de nuestros colectivos, nuevos deslizamientos o grietas que nos permitan continuar pensando. En primer lugar, y en relación con las preguntas que nos hacíamos, podemos afirmar que la reflexión deliberada como práctica se encuentra tensionada. En el quehacer de los grupos identificamos claramente la dimensión de fuerzas encontradas entre la posibilidad (apertura) y la repetición (clausura de esa reflexión). Así, hemos mostrado en este escrito situaciones en las cuales el proceso de reflexión se desarrolla y, tal vez descarnadamente también, hemos intentado poner de relieve las dificultades entre la reflexión y la deliberación, sobre todo cuando esta conjunción implica transitar y transponer la tensión, y sostener la indagación acerca de las significaciones imaginarias sociales que nos habilitan como humanos en nuestras cotidianidades. En este sentido, nos ha interesado poner en articulación los conceptos de la teoría militante de Castoriadis con teorías que para nuestros equipos son familiares, tales como los conceptos nodales de la etnografía y la sociolingüística de la interacción. Si bien en este escrito no hemos detallado la forma en que etnografía y sociolingüística informan nuestro trabajo, estas orientaciones están implícitas y en dos sentidos fuertes: por una parte, han sido de hecho puestas en práctica para trabajar en la mesa, para generar vínculos entre los grupos que la conforman, para construir archivos de información que permitan interrogar nuestra práctica, y para poner en funcionamiento estos archivos. Por otra, han operado en la forma de comprender que cada uno de nuestros colectivos construye su vida social a través de lo que en etnografía llamamos práctica cultural y que la sociolingüística de la interacción ha intentado explorar a través de la interrogación de lo cotidiano como construcciones intertextuales (Heras 1993, 1995). Por lo tanto, una primera noción teórica que nos resulta importante destacar es que creemos congruente la práctica de la 
investigación-acción colaborativa a través de la teoría de Castoriadis e informada por estas otras disciplinas que mencionamos. ${ }^{6}$

Más específicamente destacando el valor explicativo que puedan tener las distinciones que hemos buscado señalar (entre deliberación reflexiva y reflexión deliberada), podemos sostener que es poco frecuente que se ponga en marcha un proceso que interrogue sobre el sentido de lo que ocurre en los colectivos, es decir, sobre las significaciones imaginarias sociales que los guían. Al indagar específicamente sobre la deliberación nos preguntábamos si acaso deliberar sin proponerse una visión crítica sobre los sustentos o significados en que nuestras construcciones institucionales se basan es acaso casi no reflexionar, al menos en el sentido que proponíamos al principio, guiados por Castoriadis. Creemos entonces que es importante distinguir la reflexión deliberada de la deliberación reflexiva como una segunda cuestión, vinculando la potencia que nos brindan los conceptos con el recorrido que hemos hecho de análisis de nuestras prácticas. Así, proponemos que un aporte que realizamos es del orden de la praxis: creemos importante poder identificar, registrar y sistematizar los mecanismos y las situaciones que habilitan este tipo de praxis que no es otra cosa que profundizar en la autogestión como proyecto de autonomía. Por eso, sostenemos que es revolucionaria. Nos parece fundamental intentar ampliar los espacios para la reflexión deliberada por sobre la deliberación reflexiva comprendiendo el horizonte de sentido que orienta estas diferencias. Y nos resulta relevante poder explicitar este hallazgo ya que apunta a interrogarse acerca de las posibilidades de acción política, imaginación radical y democratización de grupos que se plantean ellos mismos como proyectos de autonomía.

Una tercera cuestión para nosotros es del orden del método, y se liga a lo que acabamos de proponer en el aspecto de la praxis revolucionaria (o de la autonomía como proyecto, que en la obra de Castoriadis se tornan sinónimos): nos parece importante contar con herramientas de registro de interacciones, análisis de estas, producción de cuerpos de archivos accesibles a nosotros mismos, y de espacios y tiempos previstos para volver sobre los archivos. Creemos que construcción o generación de datos para producir archivos, y al 
mismo tiempo, creación de dispositivos que permitan el uso de lo archivado, tornándolo dato en tiempo real, también es fundamental y distintivo de nuestro aporte de trabajo. Como decíamos antes, creemos que este aporte es posible por conjugar teorías y enfoques de investigación que provienen de campos diferentes pero entre los que vamos encontrando interesantes articulaciones. En esta línea, hemos intentado sostener y mostrar a lo largo del artículo que no es solamente registrar, acumular, archivar o incluso consultar este cuerpo de información, sino también cómo lo realizamos concretamente, cuando nos acercamos a consultarlo e interrogarlo. Por ejemplo, hemos propuesto que mirar desde el espejo y las formas incide en nuestra posible comprensión de esas aperturas y clausuras en los procesos de reflexión. Estas dos instancias interpretativas entonces nos orientan a ver: portan indicios. Por ejemplo, en tanto la reflexión deliberada se relaciona con el acto de «hablar con el corazón en la mano», la gestualidad, la entonación de lo que decimos, nuestras posturas corporales y miradas son instancias que entran en juego, y por tanto las proponemos también como parte de los indicios a ser analizados.

A su vez, estas tres cuestiones (de orientación conceptual teórica general, de praxis y de método) se vinculan con una cuarta y última, de orden institucional: la creación de una obra que instituya encuentros entre colectivos con propósitos a la vez claramente definidos (el autoanálisis) y a la vez claramente abiertos (es decir, que en su misma formulación de instituido se incluya la potencia del cambio, de la ampliación de cadenas de relevos psíquicos y de creaciones tales que lo indeterminado efectivamente tenga lugar y a la vez pueda ser interrogado) es a su vez un proceso que, como diría Castoriadis, se orienta por nuestra voluntad de elegir. La misma conformación de la mesa de trabajo de este proyecto de investigación que juega con la abstracción del espejo y propone distintos lenguajes (oral, visual, escrito, audiovisual, gestual) y distintos géneros expresivos dentro de cada lenguaje es un modo de habilitar y profundizar la reflexión deliberada dentro de los colectivos. Concluimos vinculando esta cuestión de orden institucional con lo que Castoriadis propone como lógica de magmas, ya que nos parece más cercana, como visión de lo que vamos creando como obra, a la posibilidad de actuar desde, con y hacia lo que es complejo por 
naturaleza, heterogéneo por factura, increíble -casi- en su ontología, puesto que es lo que aún no está creado.

Castoriadis plantea que el ser humano es el único animal que tiene la capacidad de imaginar y la capacidad de la psique de «investir» objetos libidinales, o sea, de cargar de sentido lo que hacemos. Cuando nos fuimos encontrando en la mesa colectiva, escuchamos con atención, preguntamos sobre las experiencias, sonreímos o suspiramos cuando algún relato de otro nos ha parecido propio (o impropio). Paulatinamente, los proyectos se entrecruzan en el imaginario, en las coincidencias, en las diferencias. Pensar y volver a direccionar nuestras prácticas, construir nuevas formas de llevar el proyecto del imaginario a una realidad más soñada. La no linealidad brinda al arte de crear nuestra obra institucional un abanico de posibilidades, y la no linealidad ofrece a las prácticas conjuntas y a la reflexión deliberada la elección de nuestro hacer colectivo. Escrutamos nuestro destino, soñamos. Y de alguna manera traducimos en hechos concretos esos sueños sin someternos a condicionamientos preestablecidos, eligiendo. Aunque no siempre se manifiesten nuestros deseos... Entonces seguimos buscando, cambiamos, nos encontramos con otros que nos cambian. No abandonamos el andar.

Nos surgen algunas preguntas, aún sin responder del todo: ¿qué lugar ocupa la reflexión deliberada efectivamente y cómo se sostiene, en concreto, en este tipo de colectivos de trabajo?¿Es suficiente con convocar a un espacio o pensar un dispositivo específico para que la reflexión deliberada se habilite y fluya? ¿Cómo operan en concreto las distintas subjetividades cuando actúan en interacción, tomando en cuenta que algunas estarán más condicionadas por sus determinaciones y otras serán más lábiles, pudiendo abrirse a imaginar nuevas opciones con mayor facilidad?

\section{FUENTES DE CONSULTA}

Antonietta, Fernando y David Burin, 2011, «Serie de videos sobre tecnologías apropiadas 
para la Agricultura familiar» [video], Proinder, Argentina.

Bajtín, Mijail, 1999, Estética de la creación verbal, Siglo XXI Editores, México.

Burin, David, Waldo Guerrero, Fernando Antonietta, Silvia Krementchuzky, 2010, «Alto Verde, video fortalecimiento de organizaciones de pequeños productores rurales», [video], Ediciones INCLUIR, Crisol Proyectos Sociales, CADIF, PRODERNOA, Tucumán-Buenos Aires.

Castoriadis, Cornelius, 1980, «Reflexiones sobre el desarrollo y la racionalidad», en El mito del desarrollo, Editorial Kairos, Barcelona, pp. 183-208.

1990, «Poder, política, autonomía», en El mundo fragmentado, Nordan Comunidad, Montevideo, pp. 73-97.

1997, «La democracia como procedimiento y como régimen», en El Avance de la Insignificancia. Las encrucijadas del laberinto IV, Editorial Universitaria de Buenos Aires, Buenos Aires, pp. 267-291.

2002a, «Herencia y Revolución», en Figuras de lo pensable (las encrucijadas del laberinto VI), Fondo de Cultura Económica, México, pp. 129-144.

2002b, «Imaginario e imaginación en la encrucijada», en Figuras de lo pensable (las encrucijadas del laberinto VI), Fondo de Cultura Económica, México, pp. 93-113.

2004, Sujeto y verdad en el mundo histórico social, Fondo de Cultura Económica, Buenos Aires.

2005, La lógica de los magmas y la cuestión de la autonomía, en Los dominios del hombre. Las encrucijadas del laberinto, Gedisa, Barcelona, pp. 193-218.

2006, Lo que hace a Grecia. 1. De Homero a Heráclito. Seminarios 1982-1983. La creación humana II, Fondo de Cultura Económica, Buenos Aires.

2007, La institución imaginaria de la sociedad, Tusquets, Buenos Aires.

Flury, Jorgelina, 2012, «Narrar la experiencia con otros: aprendizajes hacia la autonomía en la práctica de la autogestión», Tesis de maestría, FLACSO, Argentina.

Gadamer, Hans-Georg, 1995, El giro hermenéutico, Cátedra, Madrid.

2005, La actualidad de lo bello. El arte como juego, símbolo y fiesta, Paidós, Argentina.

Heras Monner Sans, Ana Inés, 1993, «The construction of understanding in a sixth grade 
bilingual classroom», Linguistics and Education, v. 5, n. 3 y 4, Ablex Publishing, Nueva Jersey, pp. 275-299.

1995, «Living Bilingual, Interacting in Two Languages: An Ethnographic and Sociolinguistic Study of a Fourth Grade Bilingual Classroom», Tesis doctoral, Universidad de California, California.

2009, «Ampliando la mirada. Aportes de la etnografía y la sociolingüística al estudio de procesos locales», Observatorio Social, n. 25, Asociación Civil Observatorio Social, Argentina, pp. 22-27.

2011, «Dispositivos de aprendizaje en autogestión: sus relaciones con el proyecto de autonomía», Intersecciones en Comunicación, n. 5, Universidad Nacional del Centro de la Provincia de Buenos Aires, Buenos Aires, pp. 31-64.

2012, «Perder el juicio, poder entender: cuestiones tensas y preguntas sin resolver sobre situaciones de niños /as adolescentes y jóvenes en Ciudad de Buenos Aires, Argentina», Estudios y propuestas para el medio rural, UAIM, México (en prensa).

Heras Monner Sans, Ana Inés, David Burin y Serena Colombo, 2011, «Modos de retribuir el trabajo y satisfacer necesidades de los integrantes de los colectivos autogestionados orientados hacia la autonomía», Documento de trabajo interno, en http://wp.me/pKKLw-7v [consulta: 12 de junio de 2011].

Heras Monner Sans, Ana Inés y David Burin, 2012, Retribución de excedentes en proyectos auto-gestionados. Formas de pensar y ejercer la democracia como régimen de sentido (en prensa).

\section{NOTAS}

\footnotetext{
${ }^{1}$ Idea melódica con personalidad suficiente para ser retenida por el oyente de una pieza vocal o instrumental, y que los compositores suelen usar como punto de referencia para después modificarlo, elaborarlo y mostrar su habilidad compositiva en sus evoluciones realizadas de modo que siempre sea reconocible la personalidad del tema. http://blogclasico.blogspot.com.ar/2008/02/tema-definicion-musica-tiempo-o-tempo.html

${ }^{2}$ Por ejemplo, en el libro que en español se publicó bajo el título Sujeto y verdad en el mundo histórico social (Seminarios 1986-87) desarrolla, en el Capítulo VI, una larga explicación sobre lo que denomina la subjetividad humana y su relación con las condiciones de reflexividad y voluntad, en primer término, y luego en los capítulos subsiguientes VII y VIII toma el tema de la reflexión deliberada más específicamente en sus
} 
relaciones entre psique y sociedad.

${ }^{3}$ Nuestros análisis se centraron en estudiar, por ejemplo, cómo se generan y reparten los excedentes (Heras et al. 2011, Heras y Burin 2012); cómo se piensan a sí mismos los proyectos autogestionados con orientación hacia la autonomía; qué de sus dispositivos es específico de esta orientación (Heras et al. 2011); qué vinculaciones existen entre autogestión y relaciones de género (Heras 2012); qué tecnologías son socialmente adecuadas para las organizaciones autogestionadas campesinas (Burin et al. 2010, Antonietta y Burin 2011, Burin 2012); qué situaciones y tipos de aprendizaje hacia la autonomía son narrados en materiales escritos y audiovisuales acerca de experiencias autogestionadas (Flury 2012).

4 Participan en la mesa las siguientes organizaciones: Frente de Organizaciones en Lucha http://www.fol.org.ar/, el Comedor a Cielo Abierto «El Gomero» en Barrancas de Belgrano, Ciudad de Buenos Aires, http://www.facebook.com/comedor.debarrancas, Diablo Mundo cooperativa teatral http://www.redteatralsur.com/rooms/view/4, la Unión de Músicos Independientes, http://www.umiargentina.com/ y el Instituto para la Inclusión Social y el Desarrollo Humano, Asoc. Civil INCLUIR www.incluir.org.ar. Se integrarán a la Mesa en breve el Centro de Integración Monteagudo y la Cátedra Schejter de Psicología Institucional de la UBA, Argentina.

${ }^{5}$ El teatro Independiente no se encuentra en los circuitos comerciales o masivos, por lo tanto la producción tanto artística como ejecutiva es responsabilidad de los grupos. «El teatrero» no es sólo actor o director o el rol que tenga en los espectáculos, los roles van rotando según las necesidades. Si el elenco organiza una sala, las tareas se vuelven múltiples (limpiar, confeccionar planillas, mantener el edificio, difusión, prensa, etcétera).

${ }^{6}$ En otros escritos desarrollados por nosotros se han detallado estos cuerpos teóricos y sus articulaciones, véase, por ejemplo, Heras 2009, 2011 y 2012.

\section{Fecha de recepción: 8 de diciembre de 2012.}

\section{Fecha de aceptación: 30 de junio de 2013.}

